\title{
Percepção dos médicos obstetras a respeito do parto normal
}

\section{Obstetricians' perception regarding the normal birth}

\author{
Marcos Benatti Antunes' • Ana Patrícia Araújo Torquato Lopes² • Maria das Neves Decesaro ${ }^{3}$ \\ Sandra Marisa Pelloso 4
}

\begin{abstract}
RESUMO
Objetiva-se conhecer a opinião dos médicos obstetras sobre parto normal, a fim de subsidiar a implementação de novas estratégias para aumentar as taxas desse tipo de parto. Estudo de caráter descritivo exploratório, com abordagem qualitativa, que utilizou a técnica bola de neve, obtendo uma amostra de oito médicos obstetras de um hospital de referência da Rede Mãe Paranaense. As entrevistas semiestruturadas foram gravadas e transcritas para análise.A partir da análise do conteúdo temático emergiram as seguintes categorias: Percepção do parto normal para os obstetras; A escolha do tipo de parto pelas parturientes na visão dos obstetras; e,A prevalência da cesárea versus parto normal.A partir do discurso dos profissionais participantes desta pesquisa, evidenciou-se que o parto normal é o melhor para mulher desde que a mesma não apresente riscos de possíveis complicações, uma comunicação clara entre médicos e gestantes no pré-natal e uns retornos financeiros adequados nos partos normais podem contribuir para a redução de parto cesárea e consequentemente a redução da taxa de mortalidade materna e infantil.
\end{abstract}

Palavras-chave: Parto Normal;Assistência Médica; Saúde da Mulher.

\begin{abstract}
The aim is to know the obstetricians' opinion of normal birth in order to subsidize the implementation of new strategies to increase the rates of this type of delivery. A descriptive exploratory study with a qualitative approach using the snowball technique, obtaining a sample of eight obstetrician physicians from a reference hospital of the MãeParanaense Network. The semi-structured interviews were recorded and transcribed for analysis. From the analysis of the thematic content the following categories emerged: Perception of normal delivery for obstetricians; The choice of the type of delivery by the parturients in the view of the obstetricians; and, The prevalence of cesarean delivery versus normal delivery. As of the discourse of the professionals participating in this research, it was evidenced that the normal delivery is the best for women since it does not present possible risks of complications, a clear communication between doctors and pregnant women in prenatal care and financial returns in normal deliveries may contribute to the reduction of cesarean delivery and consequently reduce maternal and infant mortality rates.
\end{abstract}

Keywords: Natural Childbirth; Medical Assistance; Women's Health.

${ }^{1}$ Enfermeiro. Doutorando em Enfermagem pelo Programa de Pós-Graduação em Enfermagem da Universidade Estadual de Maringá.E-mail: bena77i@gmail.com. Autor correspondente. Endereço: Universidade Estadual de Maringá - UEM. Avenida Colombo, 5790. CEP. 87020-900. Maringá, Paraná, Brasil.

${ }^{2}$ Enfermeira. Doutoranda em Enfermagem pelo Programa de Pós-Graduação em Enfermagem da Universidade Estadual de Maringá.E-mail:anaptorquato@hotmail.com.

${ }^{3}$ Enfermeira. Doutora em Enfermagem pela Universidade de São Paulo. Professora Adjunta do Departamento de Enfermagem da Universidade Estadual de Maringá. E-mail:mndecesaro@uem.br.

${ }^{4}$ Enfermeira. Doutora em Enfermagem pela Universidade de São Paulo. Professora Titular do Departamento de Enfermagem e Docente do Programa de Pós-graduação em Enfermagem e Ciências da Saúde da Universidade Estadual de Maringá. E-mail: smpelloso@uem.br. 


\section{INTRODUÇÃO}

A Organização Mundial da Saúde (OMS) estabelece que apenas $15 \%$ dos partos necessitariam ser operatórios, contudo, a taxa de cesárea no Brasil, apresentada entre os anos de 2005 a 2015, é a maior do mundo. Os dados oficiais do país em 2015 mostram um percentual crescente nas regiões mais ricas do país, com $60,5 \%$ no Sul e $59,1 \%$ no Sudeste, em Rondônia a taxa é a mais alta, com $66,8 \%$; e Amapá e Amazonas têm os menores, com $34,7 \%$ e $37,2 \%$ respectivamente ${ }^{1-2}$.

Na maioria dos casos o parto normal é a maneira mais segura e saudável de ter filhos e por isso precisa ser estimulado por meio de uma assistência humanizada (parto natural), segura e de qualidade. 0 partocesáreo deveria ser indicado somente quando fosse realmente necessário para proteger a gestante e o bebê. Salienta-se que a gestante tem o direito de ser informada sobre as razões que a impedem de optar pelo parto normal ${ }^{1}$.

Há muitos profissionais que ainda defendem a cesárea em qualquer circunstância, baseando-se na suposta segurança fornecida por novas técnicas de anestesia e aprimoramento do procedimento cirúrgico. Além disso, visto que a mulher tem autonomia e livre arbítrio de decidir qual a via de parto de sua preferência e o que fazer com seu próprio corpo, caberia ao médico apenas apresentar os riscos e benefícios e aceitar a escolha de sua paciente ${ }^{3}$.

De acordo com o Guia dos Direitos da Gestante e do Bebê, publicado pelo UNICEF e pelo Ministério da Saúde, a cesariana desnecessária é inaceitável, mas, se for preciso fazê-la, deve ser realizada apenas depois do início do trabalho de parto. A natureza tem ritmos e razões que cesarianas com hora marcada, por conveniências, desrespeitam o ciclo natural do ser humano. Se tudo vai bem, a cesariana é dispensável mesmo para parto de gêmeos (com ambos de cabeça para baixo), para prematuros, para gestantes adolescentes e mulheres com hipertensão moderada ${ }^{1}$.

Dados indicam que em apenas $15 \%$ dos partos devese optar pela cesariana, sendo esse procedimento somente recomendado quando: há risco de vida para a mãe, para o bebê ou para ambos; a mãe tem hipertensão grave; a gestante é soropositiva para o vírus da AIDS; sempre que a cabeça do bebê é maior do que a passagem da mãe (desproporcional); o cordão umbilical sai antes do bebê; a placenta descola antes do nascimento do bebê; a localização da placenta impede a saída do bebê; o bebê está sentado ou atravessado; e, no parto de gêmeos em que um dos bebês está sentado ${ }^{1}$.

Fica em evidência o dever da continuidade nas pesquisas dos fatores que estimulam o acentuado percentual de cesáreas no Brasil, visto que esse procedimento pode acarretar em inúmeras complicações, tanto para as mães quanto para os bebês. Além disso, os índices revelam-se muito acima do recomendado pela OMS, demonstrando que políticas públicas dirigidas à redução das taxas de cesarianas no país ainda mostram-se de caráter urgente e imprescindível ${ }^{4}$.

Desta forma,para responder aos questionamentos surgidos fez-se as seguintes perguntas norteadoras: qual sua percepção de parto normal? Fale dos aspectos positivos do parto normal para a mãe e para o bebê. Por que muitos obstetras ainda optam pela cesárea ao parto normal? Assim, objetiva-se neste estudo, conhecer a opinião sobre parto normal do profissional que vai realizá-lo, visto que os resultados podem subsidiar a implementação de novas estratégias para aumentar as taxas desse tipo de parto.

\section{MÉTODO}

Trata-se de uma pesquisa descritiva exploratória, com abordagem qualitativa, a ser desenvolvida em uma cidade da região sul do Brasil.

A pesquisa qualitativa propicia o estudo de momentos favorecidos e particulares, dos quais emergem o sentido de um fenômeno social, assente considerar os diferentes aspectos de um fato específico e relacioná-lo ao contexto geral, além da capacidade de formular proposições ligadas à ação e à prática ${ }^{5}$.

Para a identificação dos sujeitos participantes usou-se a técnica de "Bola de Neve". A técnica de "Bola de Neve" ou "Cadeia de Informantes" é uma metodologia de amostra não probabilística empregada em estudos sociais, na qual os indivíduos selecionados inicialmente indicam outros participantes, que por sua vez sugerem novos sujeitos e assim sucessivamente, até que seja alcançado o ponto de saturação das informações. Este ponto é atingido quando os recém-entrevistados passam a reproduzir os mesmos conteúdos já obtidos nas entrevistas anteriores, sem acrescentar novidades de dados à pesquisa ${ }^{6}$.

Para identificação dos sujeitos do estudo realizouse contato com um hospital referência da Rede Mãe Paranaense, que contava com 10 obstetras, 02 médicos residentes em ginecologia e obstetrícia, 02 enfermeiros obstetras e 02 enfermeiros assistenciais. Os médicos, além de atenderem no ambulatório de alto risco, realizam parto no hospital referência. Após a autorização do hospital, abordou-se inicialmente os obstetras, agendando uma visita para a entrevista com os 03 primeiros, estes, ao térmico dos questionamentos indicaram mais02 obstetras. Considerou-secomo critérios de inclusão: ser médico obstetra efetivo e plantonista no hospital referência; estar cadastrado no Conselho Regional de Medicina ena Rede Mãe Paranaense. E ainda, como critério de exclusão: a não presença do médico obstetra após duas visitas a maternidade, e o não aceite a participar da pesquisa

A escolha do Hospital referência dentroda Rede Mãe Paranaense se deve pelo fato deste realizar o parto de modo seguro e solidário, o mais natural possível, de acordo com o grau de risco da gestante, por meio de um sistema de vinculação da gestanteorganizado via HOSPSUS, programa de qualificação dos hospitais públicos e filantrópicos do Sistema Único de Saúde do Paraná7. 
A coleta de dados ocorreu no mês de novembro de 2013 com 08 obstetras, na qual os pesquisadores realizaram visita previamente agendada com o médico especialista indicado para efetivação de uma entrevista semiestruturada. Durante a entrevista também foi aplicado o instrumento para coleta de dados sociodemográficos.

Nesta ocasião, os participantes foram informados sobre os objetivos do estudo, os procedimentos adotados, sobre a livre opção em participar ou não, a possibilidade de negar a autorização retirando-se do estudo a qualquer momento que desejar, inclusive se já tiver iniciado a entrevista, e sobre o compromisso em garantir a livre participação e o anonimato das informações. Após o esclarecimento de dúvidas, o que concordou em participar do estudo, assinou o Termo de Consentimento Livre e Esclarecido.

As entrevistas foram gravadas para garantir maior interação e fidedignidade às respostas, sendo transcritas de forma integral após cada entrevista para análise dos dados. $\mathrm{O}$ fechamento da coleta de dados se deu por redundância e saturação de informações fornecidas pelos obstetras.

Para percurso metodológico no tratamento dos dados utilizou-se a análise de conteúdo temática de Bardin, que emprega a manipulação de mensagens, comunicações, para confirmar os indicadores que permitam inferir sobre outra realidade que não a da mensagem, isso é o desvelar crítico $^{8}$. Por fim, a discussão foi sustentada com base no material científico disponível na área da saúde e afins, com base no objetivo proposto.

Buscando preservar a identidade dos participantes,não foi contextualizada referência que designe nominalmente o/a obstetra de cada entrevista, sendo nomeados como deuses da mitologia grega: Hera, Apolo, Poseidon, Atena, Dionísio, Hermes, Ares e Zeus, por acreditar na representatividade e importância que estes têm para as gestantes.

0 estudo foi desenvolvido em consonância com as diretrizes disciplinadas pela Resolução $n^{\circ} 466 / 12$ do Conselho Nacional de Saúde, aprovado sob o parecer $n^{\circ}$ 479.008 do Comitê Permanente de Ética em Pesquisa com Seres Humanos da Universidade Estadual de Maringá (COPEP).

\section{RESULTADOS E DISCUSSÃO}

Fizeram parte deste estudo 08 médicos, todos atuantes tanto no serviço público quanto no privado. A idade variou entre 32 e 48 anos, sendo 06 do sexo masculino e 02do feminino. Quanto ao tempo de formação acadêmica a média foi de 10 anos, sendo 05 anos o mínimo e 24 anos o máximo. Destaca-se que dos 03 médicos que têm filhos, totalizando 06 experiências de parto, apenas 02 nasceram de parto normal (Tabela 1).

$\mathrm{Na}$ análise de dados emergiram três categorias temáticas: "percepção do parto normal para os obstetras", "aopção do tipo de parto pelas parturientes na visão dos obstetras" e "a prevalência da cesárea versus parto normal".
Tabela 1. Características da amostra, Paraná, 2013.

\begin{tabular}{l|c|c}
\hline \multicolumn{1}{c}{ Caracterização } & Feminino (n=2) & Masculino (n=6) \\
\hline Estado Civil & $0(0 \%)$ & $1(16,7 \%)$ \\
\hline Solteiro & $2(100 \%)$ & $5(83,3 \%)$ \\
\hline Casado & $1(50 \%)$ & $2(33,3 \%)$ \\
\hline Tem filhos & $1(50 \%)$ & $4(66,7 \%)$ \\
\hline Sim & $2(100 \%)$ & $5(83,3 \%)$ \\
\hline Não & $0(0 \%)$ & $1(16,7 \%)$ \\
\hline Especialização & \\
\hline Ginecologia e Obstetrícia & $(100 \%)$ & $0(0 \%)$ \\
\hline Reprodução & $0(0 \%)$ & $5(83,3 \%)$ \\
\hline Tempo de formado & $0(0 \%)$ & $1(16,7 \%)$ \\
\hline Até 10 anos 20 anos &
\end{tabular}

Fonte: dados da pesquisa.

\section{Percepção do parto normal para os obstetras}

Os relatos evidenciam a percepção de parto normal pelos obstetras, mencionando que é a melhor via de parto, desde que não se apresente nenhuma contraindicação ou possível intercorrência na realização do mesmo.

"Em minha opinião, o parto normal é a melhor via de parto, tanto pra mãe quanto para o bebê, desde que não tenha nenhuma condição, nenhuma situação que indique um risco aumentado ou alguma contraindicação para o parto normal." (Hera)

"Eu acho que o parto normal seguro é menos complicação pra mãe, mais saudável para o bebê. [...] porém é uma coisa complicada, [...] principalmente no sistema particular." (Apolo)

“Bom! Parto normal a gente sabe que para o feto é muito melhor, a própria natureza já é normal [...] tem a descida dele do canal de parto [...] não tem corte, não tem nada." (Dionísio)

"[...] parto vaginal espontâneo [...] na minha concepção é o melhor método, melhor meio de nascimento do bebê. Grandes são os benefícios tanto para o neném quanto pra recuperação da mãe." (Hermes)

“Parto normal pra mim é a melhor forma de um bebê nascer, desde que não haja nenhuma intercorrência [...] melhor que cesárea. [...] deixa a cesárea só pra casos de emergência ou urgência." (Ares)

"Minha percepção de parto normal é que é um parto normal, para aquela mulher que quer, deseja e que tenha condições de ter um bom acompanhamento durante o trabalho de parto." (Zeus)

0 consenso entre os entrevistados aponta para uma aceitação ao procedimento parto normal, visando condições fisiológicas, psicológicas, de bem-estar e de recuperação adequada tanto para a mãe quanto para o bebê. 0 posicionamento em realizar a cesárea em situações de risco também é sinalizado, bem como aspectos ligados 
ao sistema particular de saúde, que podem influenciar na escolha da via de parto.

Compreende-se que os profissionais de saúde têmgrande significância na execução do parto humanizado, visto que são intercessores deste processo,sendo assim, torna-se primordial seu comprometimento para tornar o parto o mais natural possível ${ }^{9}$.

Ao se realizar inferências aos relatos dos participantes, podemos relacioná-los aos inúmeros programas, políticas e iniciativas para humanizar a assistência durante o prénatal e nascimento, as quais buscam o resgate da ação ativa e focal da mulher em seu parto, garantindo um trabalho natural ao dar à luz e uma melhor condição de saúde para a mãe e bebê, diminuindo as intervenções intensivistas, e fornecendo a segurança necessária para um bom processo de nascimento ${ }^{10}$.

Diversos pontos positivos sobre a realização do parto normal foram relatados.

\begin{abstract}
"É menos risco de complicações cirúrgicas pra mãe, tardia, imediata, menos risco de infecção, menos risco de dor crônica, menos risco de lesão [...] menos dor no pós-operatório. E para o bebê o próprio trabalho de parto estimula o sistema respiratório [...] questão de amamentação, de movimento, e tem até uma questão do tempo, que tem estudos que indicam que as substâncias que o bebê secreta no líquido quando ele está com a maturidade pulmonar adequada, desencadeia o parto normal. Às vezes o parto normal pode ser até um indicativo de maturidade real e não esperada." (Apolo)
\end{abstract}

“Para o bebê é inquestionável [...] porque durante o trabalho de parto, o bebê tem todo aquele estresse de trabalho de parto, da movimentação [...] o bebê expele os líquidos que ficam dentro dele, então nasce um bebê melhor, mais corado, um bebê que chora melhor [...] bebê de cesárea você corta e tira o neném, ele não está preparado. [...] E pra mãe, também, dor, vai ter [...] mas a hora que nasce o neném, a dor acaba, a barriga volta ao normal, a recuperação da mulher é muito mais rápida, sangra menos, a paciente dentre uma a duas horas já pode comer, já está caminhando. [...] e na cesárea a gente vê que não é assim, a mulher fica vários dias com dor, desconforto, não tem dor antes, mas vai ter depois." (Atena)

“Para a mãe [...] a recuperação é mais rápida, ela pode levantar e andar logo após um parto normal, ela já está apta para amamentar o bebê, então já é uma vantagem pra ele. Não vai ter um corte na barriga, o tônus uterino é mais eficaz, ela vai sangrar menos [...] a cesárea já é o contrário disso, essas são as vantagens do parto normal." (Ares)

O contexto apresentado pelos profissionais sobre os pontos positivos do parto normal apoia-se em perspectivas ligadas a um conforto tanto para a mãe quanto para o bebê, sinalizando a importância de um nascimento no momento ideal. Evitando, de certa forma, o estresse neonatal e estimulando a criança a desenvolver suas funções primárias, bem como a possibilidade de uma amamentação precoce que contribuirá com a recuperação da mãe, estreitamento dos laços entre eles e os outros inúmeros benefícios do aleitamento materno.

O parto normal apresenta inúmeras vantagens em relação à cesariana, a recuperação no período puerperal e do corpo da mulher é mais rápida, pois seu fisiológico foi preparado para isso, não precisa se expor a cirurgias, o índice de hematomas ou infecções é menor para mãe e filho, a dor pode ser evitada, com técnicas de analgesia e há redução do desconforto respiratório do recém-nascido (RN),permitindo que o mesmo obtenha melhor vitalidade pós-nascimento ${ }^{11}$. Porém, existem muitos tabus e fragilidades acerca de informações sobre o parto normal,o que de certa forma,mediante pré-conceitos historicamente construídos,pode conduzir a um pensamento hegemônico de que o parto cesáreo é o mais adequado simplesmente pela ausência de conhecimento sobre o parto normal.

\section{A opção do tipo de parto pelas parturientes na visão dos obstetras}

Os obstetras, por sua vivência, relataram que a escolha da gestante pelo tipo de parto é, em sua maioria, a cesárea, e isso se deve aos fatores relacionados a aspectos sociais e culturais.

Algumas falas direcionam-se às crenças relacionadas à dor:

"A maioria das mães, a principal preocupação delas em relação ao parto normal é a dor, que tem medo de sentir a dor do parto [...]." (Hera)

"[...] tudo depende muito da cultura, aqui no Brasil, fica esse negócio de cesárea embutido na cabeça das mães, então todo mundo, a maioria, acha que vai ter cesárea...assim, 80\% das mães falam assim...eu quero ter cesárea, não quero sofrer [...]." (Atena)

"Aqui no Brasil é $100 \%$ cesárea; Porque aqui se criou
essa política da cesárea, elas não querem ter dor."
(Poseidon)

“Cesárea, a maioria das pacientes quer cesárea porque têm medo da dor do parto, tem medo de alargar o canal vaginal, ela acha que vai perder a função sexual." (Ares)

Estes trechos levam-nos a conceber que o aspecto social e cultural tem grande predominância nas decisões das mães, e isso vem tendo desdobramentos que reforçam a ideia de que o parto cesariano é menos doloroso e mais seguro, gerando até mesmo uma inversão de valores, pois o parto "natural", dito normal, acaba sendo visto com maus olhos e evitado por grande parte das gestantes.

Vários aspectos podem contribuir para essa "inversão" como, por exemplo, os fatores socioculturais que influenciam a escolha pela cesariana, os quais abrangem questões ligadas ao medo da dor do trabalho de partoe uma possível realização da episiotomia. Tais anseios, muitas vezes são difundidos pela grande mídia e pela própria população brasileira, fazendo com que as mães, 
com medo de sentir dor, procurem serviços particulares de cesárea eletiva marcando com antecedência, escolhendo o médico, dia e hora do procedimento, tudo isso em vista da crença que ela não terá dor ${ }^{10}$.

O outro ponto destacado nos discursos é de que a escolha pela cesárea também acontece devido àfalta de orientações que as parturientes recebem o baixo nível educacional, a estrutura do sistema político, econômico e social, e a possibilidade de ser planejável e rápido.

"Acredito que, primeiro por ser agendada, ela sabe o dia e hora que vai nascer, avisa a família, já tira férias do trabalho, toda uma questão logística." (Apolo)

"Parto cesárea [...]falta de orientações de alguns profissionais, falta de estrutura no sistema geral [...]." (Poseidon)

"[...] a cesárea, opção dela e infelizmente do obstetra, uma questão da rapidez no procedimento." (Hermes)

“A maioria escolheria cesárea (e porque?) despreparo, falta de educação [...] de pai e mãe." (Zeus)

Tais discursos remetem a uma escolha projetada pelos pais e médicos, visando uma organização prévia e atribuindo facilidades para os envolvidos, essa percepção geralmente não tem como foco a criança, os participantes no evento - pais e médicos - esquecem-se do personagem principal, simplesmente pela comodidade em se metodizar a agenda da família e/ou do profissional, pela rapidez do procedimento.

Outro aspecto levantado foi o despreparo dos envolvidos nesta decisão,esse despreparo e falta de educação, mostram um descontentamento com pais que muitas vezes não estão informados para tomar decisões perspicazes, sendo conduzidos a ações que buscam simplesmente resolver a situação, o que problematiza ainda mais a utilização do parto cesárea de forma inadequada.

Assim, o medo das mulheres em parir da forma normal pode ser decorrente da falta de orientações dos profissionais da saúde para com a paciente, possibilitando a resposta de todas as suas dúvidas, anseios e dificuldades ${ }^{12-13}$.

Esses receios fazem com que o procedimento de cesárea torne-se cada vez mais comum, haja vista que ele deveria ser usado para salvar vidas (mãe-bebê) em partos de riscos, e não realizado de forma corriqueira, contribuindo para a sua associação à mortalidade materna infantil. Desta forma, a cesárea, sendo uma intervenção cirúrgica, deveria ser praticada apenas quando há perigo eminente para mãe-bebê $\hat{e}^{14-15}$.

Contribuindo com o medo do natural, a falta de informação e tempo, a grande mídia mostra o trabalho de parto normal como sendo algo de muita demora e sofrimento, e isso é revelado na fala de um dos obstetras.

“Já é a cultura do Brasil, da cesárea, elas mesmas têm medo do parto, da dor [...] a televisão (grande mídia) mostra aquelas mulheres ganhando (bebê) embaixo da árvore, morrendo de dor, gritando, então tudo aquilo assusta, não é verdade." (Dionísio)

Tal cenário remete a um momento delicado, criandose um senso comum de que a cesárea é mais adequada, e que o próprio termo "normal" outra forma de dar à luz, sendo erroneamente interpretado como um processo de sofrimento para a mãe, levando cada vez mais mulheres a optar pela via abdominal.

Asdiscrepâncias entre a percepção dos médicos quanto apreferência das mulheres e a real escolha das mesmas sobre a via do parto é exibido em um estudo ${ }^{16}$ que mostra que a opinião/predileção do obstetra nem sempre é a mesma das mulheres. Para acalmar essa divergência, os autores sugerem o aprimoramento e ênfase das orientações às gestantes,um meio de reduzir as taxas de cesárea e outras complicações, como estratégia em dizimar a mortalidade materna e infantil.

Para a desconstrução de mitos errôneos torna-se importante o desenvolvimento de atividades educativas realizadas pela equipe de saúde, permitindo sanar dúvidas e questionamentos, diminuindo a ansiedade e dor,as quais podem proporcionar o afastamento do medo de todo processo gestacional, além de oferecer acolhimento e tranquilidade à gestante ${ }^{17}$.

\section{A prevalência da Cesárea versus Parto Normal}

Os depoimentos dos participantes do estudo evidenciam inúmeras situações que levam a escolha da cesárea pelos obstetras, e estas se definem em:aspectos financeiros, contraindicação ao parto normal, agilidade e vontade da própria paciente.

"Eu acredito que a maioria das vezes uma contraindicação ao parto normal, mas se não tiver essa contraindicação é para satisfazer o desejo da paciente." (Hera)

“[...] os obstetras optam pela cesárea por dois motivos, primeiro pela pressão da paciente que geralmente usa particular e convênio [...]. E outra questão é a financeira mesmo, apesar do parto normal que em muitos convênios e SUS paga mais que a cesárea, é uma diferença que não compensa. [...] independente do valor de um convênio pro outro, a cesárea, o cara agenda, vai opera, uma hora, uma hora e meia, e tal [...] e já volta pra atividade. O parto normal você tem que ficaracompanhando a paciente durante o trabalho de parto [...]." (Apolo)

"Se uma paciente do consultório, e se for ainda de convênio, ele (obstetra) não vai querer parto (normal), ele vai querer cobrar particular, ou ele vai querer cesárea, porque financeiramente, para o médico não compensa; porque ele tem que ficar lado a lado com a paciente." (Atena)

"Eu acho que nos obstetras é o fator financeiro, como que alguém vai cuidar de um trabalho de parto e largar um consultório hoje, e vai cuidar de um trabalho de parto com o que o convênio paga pra gente... Você está pagando pra trabalhar." (Dionísio) 
“[...] a prática, a rapidez com que o médico volta ao seu serviço de rotina." (Hermes)

Justificando as altas frequências de nascidos pela cesárea. Fica evidente o posicionamento dos profissionais quanto a prevalência destaintervenção cirúrgica, acontecendo mediante a insistência ou desejo da paciente, que acredita ser a melhor opção.

Outro aspecto que se mostra relevância é que, mesmo sugerindo que a cesárea deve ser realizada apenas em casos de contraindicação ao parto via vaginal, o fator financeiro foi um motivo bem destacado entre os participantes do estudo, ou seja, os médicos têm que dispor de um tempo maior no decorrer do parto normal para o acompanhamento junto à parturiente até o ato do parir, isso faz com que deixe de examinar outros pacientes ou desenvolver atividades em consultórios, atendendo mais em menor tempo com um retorno financeiro maior.

Os médicos podem acatar o desejo da paciente quanto ao tipo de parto, isso é eticamente permissível, e desta forma ele garantirá o direito de autonomia, contudo, ele tem a responsabilidade de responder a todas as indagações da paciente e oferecer as informações a respeito do procedimento e as possíveis formas de parto ${ }^{15-18}$.

Entretanto, alguns estudosrelatam que o argumento que caberia ao médico de apenas aceitar a decisão de sua paciente quanto à escolha do tipo de partonão acontece de fato, visto que a real escolha das gestantes é o parto normal ${ }^{19-20}$.

Este cenário é reproduzido mediante o quadro em que a cesárea também é vista como um "bem de consumo", em clínicas particularese alguns hospitais privados o número de parto normal é quase nulo, isto, geralmente, se deve ao fato de os médicos não serem submetidos a protocolos internos e a mulher por conveniência, acaba escolhendo a cesárea ${ }^{10-15-17}$.

A partir dos relatos, fica evidente a tensionalidadedo ser humano em decidir o tipo de parto a realizarse, seja ela tomada pelamulher, casal, médicos ou em conjunto. Essadeliberação, muitas vezes pode ser afetada por questões culturais, familiares e até profissionais. A "autonomia" velada, aparentemente pessoal, que sofre interpelações das mais diferentes influências pode afetar a escolha entre um tipo de parto ou outro, fazendo com que os responsáveis acreditem estarem tomando a decisão mais correta e acertada para o momento, fugindo assim dos possíveis tabus e pré-conceitos que assolam esse momento tão importante na vida da mãe e do bebê, fazendo com que se reproduzam ações que acabam ganhando uma demarcação cultural, pelas inúmeras vezes que se repetem.

\section{CONCLUSÃO}

A realização deste estudo possibilitou a compreensãoda opinião dos profissionais médicos obstetras frente à realização do parto normal, das motivações para a escolha do tipo de parto feito pelas mulheres e das possíveis causas da prevalência de cesariana.

A partir do discurso dos médicos obstetras participantes desta pesquisa, conclui-se que o parto normal é o melhor para mulher desde que a mesma não apresente riscos possíveis de complicações, devendo ser indicado a realização de uma cesárea. Estes profissionais exercem papel importante na decisão da mulher, que vai se estruturando no acompanhamento do pré-natal. Eles são os protagonistas em orientar e quebrar tabus e paradigmas das gestantes quanto a vontade "velada" de fazer o parto cesárea, o medo da dor e de parir ou outros motivos culturais que a gestante expressa durante suas consultas, que podem levá-la a dúvidas na escolha do tipo de parto.

O estudo evidenciou que o fator econômico é uma causa para o grande número de cesáreas, pois o médico gasta muito tempo no parto normal com um retorno financeiro pequeno, enquanto para a cesárea gasta pouco tempo, tendo a possibilidade de fazer vários partos e ainda atender consultas com um retorno financeiro melhor.

Desta forma, uma melhor comunicação entre médicos e gestantes no pré-natal e um retorno financeiro melhor nos partos normais, podem contribuir para a redução de parto cesárea e consequentemente a redução da taxa de mortalidade materna e infantil. Bem como ações governamentais que divulguem os benefícios do parto normal, visando romper com os padrões hegemônicos de uma decisão que muitas vezes é feita pela mãe simplesmente pelo fato de não conhecer os aspectos positivos do parto natural.

\section{REFERÊNCIAS}

1. Fundo das Nações Unidas para a Infância (UNICEF). Guia dos Direitos da Gestante e do Bebê. São Paulo: Globo; 2011.

2. Brasil. Ministério da Saúde. Datasus. Informações de Saúde. Nascidos vivos [Internet]. 2015. [acesso em20 ago 2017]. Disponível em: http://tabnet.datasus.gov.br/cgi/tabcgi. exe?sinasc/cnv/nvuf.def.

3. Ferrari J. Preferência pela via de parto nas parturientes atendidas em hospital público na cidade de Porto Velho, Rondônia.Rev. Bras. Saude Mater. Infant. 2010; 10(Suppl 2): s409-s417.

4. Meller FO,Schaffer AA. Fatores associados ao tipo de parto em mulheres brasileiras: PNDS 2006. Ciênc. saúde coletiva. 2011; 16(9):3829-3835.

5. Minayo MCS. O desafio do conhecimento: pesquisa qualitativa

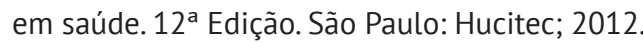

6. Albuquerque EM. Avaliação da Técnica de Amostragem "Respondent-DrivenSampling" na Estimação de Prevalências de Doenças Transmissíveis em Populações Organizadas em Redes Complexas [dissertação]. Rio de Janeiro (RJ): Escola Nacional de Saúde Pública Sérgio Arouca; 2009.

7. Paraná. Secretaria Estadual de Saúde (SES). Linha Guia: Rede Mãe Paranaense. Paraná: Editora da SES; 2015. 
8. BardinL. Análise de conteúdo. São Paulo: Edições 70; 2011.

9. Carvalho VF, Kerber NPC, Busanello J, Gonçalves BG, Rodrigues EF, Azambuja EP. Como os trabalhadores de um Centro Obstétrico justificam a utilização de práticas prejudiciais ao parto normal. RevEscEnferm USP. 2012; 46(1):30-37.

10. Almeida NAM, Medeiros M, Souza MR. Perspectivas de dor do parto normal de primigestas no período pré-natal. Texto contexto enferm. 2012; 21(4):819-827.

11. Carneiro R. Daquilo que os médicos quase não falam: transe e êxtase na cena de parto. Experiências e percepções dissidentes de saúde e de bem-estar na contemporaneidade. Ciênc saúde coletiva. 2013; 18(8):2369-2378.

12. Jamas MT, Hoga LAK, Reberte LM. Narrativas de mulheres sobre a assistência recebida em um centro de parto normal. Cad Saúde Pública. 2013; 29(12):2436-2446.

13. Sodré TM, Merighi MAB. Escolha informada no parto: um pensar para o cuidado centrado nas necessidades da mulher. CiencCuid Saúde. 2012; 11(suplem.):115-120.

14. Bittencourt F, Vieira JB,Almeida ACCH. Concepção de gestantes sobre o parto cesariano. CogitareEnferm. 2013; 18(3):515-20

15. Leal MC. Estar grávida no Brasil. Cad. Saúde Pública. 2012; 28(8):1420-1421.

16. Gonçalves AK, Missio L. Fatores determinantes paraas expectativas de gestantes acerca da via de parto.In: $7^{\circ}$ Encontro de Iniciação Científica. Dourados: UEMS [Internet]. 2009 [acesso em 10 ago 2014].Disponível em: http:// periodicos.uems.br/index.php/enic/article/view/1978.

17. Leão MRC, Riesco MLG, Schneck CA, Angelo M. Reflexões sobre o excesso de cesarianas no Brasil e a autonomia das mulheres. Ciênc saúde coletiva. 2013; 18(8):2395-2400.

18. Pimenta LF, Ressel LB, Stumm KE. A construção cultural do processo de parto. J res: fundam careonline. 2013; 5(4):591598.

19. Velho MB, Santos EKA, Brüggemann OM, Camargo BV. Vivência do parto normal ou cesáreo: revisão integrativa sobre a percepção de mulheres. Texto contexto enferm. 2012; 21(2):458-466

20. Vogt SE, Diniz SG, Tavares CM, et al. Características da assistência ao trabalho de parto e parto em três modelos de atenção no SUS, no Município de Belo Horizonte, Minas Gerais, Brasil. Cad. Saúde Pública. 2011; 27(9):1789-1800. 